\title{
ON THE IMPORTANCE OF CONTINUING EDUCATION IN UNPREDICTABLY CHANGING ECONOMIC CONDITIONS
}

\author{
Andrej Cvetkovski \\ Assoc. Prof. Dr., Mother Teresa University, North Macedonia, acvetk@gmail.com
}

\begin{abstract}
No school, no faculty today, when everything is changing so fast, can claim to form educated people with complete and final knowledge in their profession at graduation time. One of the main tasks of educational institutions should then be to teach their students to learn how to learn throughout their lives, embracing the paradigm of continuing education. We argue that diversified education forms with strong emphasis on continuing education, as opposed to classical education models, are necessary for ensuring employability and livelihood in unpredictable economic conditions. It must be acknowledged that even the developed countries cannot boast that they have harmonized the classical education system with the needs of continuing education for retraining and lifelong professional development. In this paper we also set forth a number of recommendations for improving the educational capacities to provide continuing education through well thought-out and planned reforms, taking as a model the current situation of the education system in North Macedonia.
\end{abstract}

Keywords: Education Policy and Administration, Education System Reform, Continuing Training

\section{INTRODUCTION}

The education system is organized as one of the fundamental pillars of the the social system. Education enables the acquisition of knowledge and skills for performing professional duties and harmonizes the behavior of the individual with the behavior of other members in the community.

Due to the paramount importance of education for the humankind and the development of the human society, societies and states strive to postulate the education as a major goal of in the life of every individual, through which every member of the society is given the opportunity to acquire knowledge and skills leading to a productive work career. The education process also includes the possibility for retraining, i.e. changing a profession, as well as continuing education with the aim of maintaining employability throughout the work life.

In order for an individual to be employable and able to fulfill job duties productively, he or she needs to have a certain trade as a set or skills, or profession.

The term trade should be understood as a set of abilities and skills of varying scope, content and complexity, needed to perform some manual or mechanical work or craft, a business or occupation. For the performance of those tasks, it is necessary for the individual to possess both psychological and physical abilities and 
appropriate type and level of theoretical knowledge in addition to the practical skills. The term is broad enough and covers positions at all technological levels of the production and other industries. Trades are usually evolving conditioned on the technological advances in the production process.

The notion of profession refers to a calling that, in contrast to the trade, requires highly specialized knowledge and often long and intensive academic preparation in science or arts in order to perform it. The profession is in a more favorable position compared to the trade in that it is less dependent on the current state of technology. While trade primarily refers to the division of manual labor, the profession pertains mostly to the intellectual division of labor.

The notion of a professional qualification, on the other hand, should be understood as a set of abilities, qualities, accomplishments or skills that make an individual fit to exercise some function or position, or perform work duties of a certain type. Professional qualification, as a term, applies to both the manual and the intellectual division of labor.

The concept of retraining refers to a change of trade or occupation, for the purpose of horizontal movement of individuals in the system of professions. Retraining does not mean a change in the level of professional competence, i.e. qualification. Adult training is done for the purpose of specialization for new occupations or for professional development in the occupation that the individual works.

Every trade and profession has an objective and a subjective aspect. The objective aspect represents the actual employment and the job tasks performed in the workplace for the purpose of earning a wage or salary. The subjective aspect pertains to the possession of the necessary skills, abilities, education and vocational qualifications that fit the individual to perform a group of tasks, regardless of whether the individual is employed or seeks employment to perform them.

The objective and the subjective aspect of trades or professions have mutual conditionality and are interrelated. This is important to understand in order to overcome both the classical pedagogic system, which equates trades professions to the subjective aspect of possession of prescribed knowledge, and the 'career' understanding, which emphasizes on the objective aspect, reducing trades and professions to performance and advancing in the workplace.

The rest of this paper is organized as follows. Section 2 discusses the importance of having a national classification of trades and professions and the need of keeping it up-to-date in support of the continuing education in unpredictably changing economic conditions. Section 3 points out to the importance of having a unified system for regular and continuing education and reviews the particular issues in the current practice of North Macedonia regarding the integration of continuing education of teachers and the state system of education. Section 4 discusses details of the teacher training programs taking as a model the current situation in North Macedonia. Section 5 goes on to provide recommendations for improvement of the education system, as a starting point of a quality integration education of regular and continuing education. Concluding remarks are given in Section 6.

\section{NOMENCLATURE AND CLASSIFICATION OF TRADES AND PROFESSIONS}

The accelerated development of computer-aided manufacturing technology dictates profound changes in the traditional system of trades and professions both in terms of job descriptions and the taxonomy of qualifications. Many job positions lose their significance, and there is a trend of creating new and different positions and specialties. Previously broadly-defined occupations are transformed to narrow specializations. The vocational qualifications based merely on skills and experience become less important and even unnecessary. Qualifications requirements based on scientific and complex technological foundations, with theoretical and engineering knowledge dominate the job market. So, there is a continuing need for changes in qualifications hierarchy.

The rapid change of trades and professions caused by modern industrialism also changes the value system of the employees. The psychological motivation for work is reduced. Employees do not focus on work well done, but on good earnings and better working conditions. An additional factor that affects the workforce is the reduced guarantees of employment stability and the permanency of the type of work being done.

This gives rise to the question: How to harmonize the contemporary requirements for high work productivity with the work qualifications, trades and professions? To achieve this goal, it is necessary for the state to develop and continuously upgrade the official national nomenclature and classification of trades and professions, which, in turn will have effect both on the education system and on the job market.

Several mechanisms are expected to improve with a revised and up-to-date nomenclature and classification of trades and professions. First, the statistical monitoring and reporting on the personnel potential of the 
country will become more descriptive and closer to the actual situation. Second, the mediation in the employment process will become more efficient. Third, the professional orientation during the education phase will be well founded and suited for the reality on the job market. Fourth, professional orientation during the retraining of the unemployed will also gain on efficiency.

According to this, the nomenclature and classification of trades and professions should be designed toward training for the primary purpose of rational employment. This requires precise specifications of the profiles for trade and profession and appropriate educational plans and programs based on up-to-date job profiles and descriptions.

In North Macedonia, today the nomenclature and classification of trades and professions consists of a list of trades with the corresponding qualifications. It serves only for statistical monitoring and reporting on the country's personnel potential and employment mediation. The list does not correspond to the needs of the economy for certain occupations; it is not updated regularly and is not at all in the function of professional orientation and professional retraining. It does not set requirements for development of the education system and development of appropriate educational plans and programs for regular education, for retraining and for vocational training.

The education system of the Republic of North Macedonia, created under the auspices of the former socialist state, for more than 70 years continues to operate almost exclusively in the shadow of the governmental power and depends on its monies. Therefore, that system is a realm in which a number contradictions manifest. In the present day, these contradictions are intensified due to the slow changes in the education system in contrast with the unpredictable changes in the living, social and economic conditions.

The socio-economic position of the educational institutions, being imposed by the state, does not allow the education system to develop more rapidly into a field sufficiently open and capable to meet the social needs for transferring knowledge and work competences. That system has neither a concept nor a methodology of recognizing those needs and to harmonize its content and organization of work. Therefore, regular education, consisting of secondary and higher education, is not capable of overcoming the scarcity of various specialties which in turn hinder national development. The current education system creates staff with secondary and higher education. But can the economy create enough such jobs to suit the expertise of graduates? This problem creates severe political consequences today and will continue to do so in the future. Young people who graduate from high school or university and gain a certificate or diploma and do not find a job are bound to experience resentment for having been treated unfairly by the state system. The socio-economic system, through education, instead of creating educated and productive citizens, creates individuals who feel contempt the education system and the society. In that way both the system and the people are exposed to unanticipated consequences of the classical education system - the boomerang effect.

The boomerang effect inevitably creates a storm that results in mismatch of the education system and the needs of national development, affecting the unemployment rate. Unemployment of the youth, despite the education credentials they hold, is an increasingly serious public problem. It is the resolving or not resolving this problem that should be one of the major performance indicators the parties currently in power.

And here another essential question arises: Does regular education offer what the economy needs and does the economy productively absorb the existing workforce? The days of mass employment actions, without any criterion on expertise, are an artifact of the past. The time for reforms is also a time for clearing the overstaffed and the unqualified as redundant employees. What is next for the laid-off? Retraining and continuing education. These candidates will have to accept the new reality and reduce their pretensions to the level at which they can find a job. After all, they will have to overcome the aversion to manual labor in factory halls and agricultural and livestock farms.

If the classification of trades and professions determines the overall organization of education, what must be done? The state needs to develop a scientific methodology for analysis of trades and professions using the input from associations of employers and hire the most professional staff for each particular field. Based on that methodology, the state needs to develop a nomenclature and classification of trades and educational plans and programs for regular education and for retraining and vocational training, with a major aim of aiding the socio-economic development of the country.

\section{EDUCATION FOR REQUALIFICATION AND CONTINUING PROFESSIONAL DEVELOPMENT}

In North Macedonia, the regular education system for education of the youth on one hand, and the retraining and vocational training aimed at adult and specialty education on the other hand, have been established as 
two mostly independent subsystems.

For many years a primary quality of the regular education system was considered to be its strict order and rigidity, while the system of retraining and vocational training remained undervalued and underestimated. This was particularly pronounced in the former socialist state, which equated the educational success of the individual with the receipt of an exalted academic degree and a formal diploma, and not necessarily with functional knowledge. In today's conditions of fundamental social and economic change, diplomas and degrees gradually lose their luster if they do not belong to an individual who is at the same time sufficiently educated and capable of practicing the claimed skills.

The acquired regular education must be continuously supplemented, i.e. it requires constant professional development during the working life of the individual. The inability to employ certain staff profiles implies the need for their retraining. These activities can only be realized through continuing education. Here, too, it is to be emphasized that regular and continuing education must be interrelated and must complement each other. In the contemporary context, this mutual relation is a necessary condition for successful professional career and for promoting the position of individuals on the labor market. Therefore, for retraining and continuing training, the effort for designing a functional education system as a whole must be permanently residing on the to-do list of the authorities - the state, schools and higher education organizations, scientific research organizations, and the public institutions.

Education as a whole - including continuing education - motivates the individual and causes the nations to progress faster. However, continuing education is often left on the margins of society, as if it unnecessary or to be forgotten. There is a lot of talk that it should not be marginalized, that it is a necessary and an important factor in employment and social development. However, in practice, continuing education is not set on solid foundations, for several reasons. First, it lacks basic regulation - as principles upon which it will hinge and function in the real world. Second, it lacks plans and programs harmonized at the national level pertaining to the retraining profiles and for professional development of occupations in demand. Third, there is no organizational framework for that type of education, again, at the national level. If retraining and professional development are of strategic importance for the development of society, its solid foundations cannot be laid by education centers within companies, adult education centers, or vocational secondary schools.

\section{TEACHER PREPARATION PROGRAMS}

The strategy for continuing education must be built at the national level. Some effort in this direction, at the regulatory level, has been made in the area of professional and pedagogical training of school principals, teachers and expert associates in the schools in North Macedonia. Namely, for the principals, teachers, associates and educators, an obligation has been created for them to permanently professionally improve during their working life. The regulatory foundations for this important activity are contained in the Law on Primary Education and the Law on Secondary Education of North Macedonia. Obviously, the state must care about the permanent education of the staff in primary and secondary schools, so that it does not happen that teachers are passing only past and obsolete knowledge to the students being prepared for the future of the society, since that way, the society, slowly but surely, is to remain without a future.

With the introduction of the legal foundations allowing the universities in North Macedonia to independently offer and realize training of future pedagogues via the teacher preparation programs, the artificial barriers that supported the harmful separation of the regular and continuing education for professional training for too long, have been finally knocked down, at least in the realm of teacher training. The ability of the state and the universities are actually put on test through the teacher preparation programs.

The cooperation between the state and the universities in the field of teacher preparation must be thorough, well-thought-out and lasting, in order for the system to be successful. A number of details need to be well planned and specified, in particular: (1) the contents important for the professional, pedagogical and psychological development of the principals, teachers, professional workers and educators; (2) the types or forms of education through which those contents will be realized; (3) the manner and of realization; (4) the time period of coverage of the staff with permanent education during the working life; (5) evaluation of the achieved success in each form separately; (6) valuing the success achieved in advancing the profession; and (7) reward according to merit within the education system.

\section{RECOMMENDATIONS FOR REFORM OF THE EDUCATION SYSTEM}

The results of an assessment of the education system in North Macedonia by OECD have been published in 2019 for the needs of UNICEF and the Ministry of Education and Science of the country. A major conclusion of the assessment is that in spite of the progress done in strengthening the capacity of educational institutions and improving the access to them, a major strategic reform is still needed in order to improve the 
quality of the outcomes. The assessment goes on to provide policy recommendations for overcoming the currently identified issues in the education system. The main issues and recommendations of the assessment are briefly summarized in the following.

\subsection{General Issues}

The number of universities in North Macedonia has increased by a factor of 4.4 in the last 15 years (from 5 in 2004 to 22 in 2019), which implies, at least in theory, a major increase of the opportunities and the participation of the youth in the higher education. The rate of employment of the graduates from universities, however, remains significantly lower compared to the EU graduates (55\% vs. $83 \%)$. The obvious conclusion from this outcome is that a mere increase in the quantity is not a good strategy, as it does not imply an increase in quality or suitability.

The report emphasizes that higher-education programs do not reflect the needs of the labor market. Among the major identified issues are the long-standing lack of effective quality controls, the lack of selectivity of the enrollment process, enabling students with apparent gaps in their prior preparation to enter university, and absence of clear curriculum outcomes and goals to achieve. In North Macedonia there is an urgent need to establish a body for monitoring the learning process and defining goals and outcomes to be achieved by the teaching and learning process.

\subsection{Recommendations for Training of Teachers}

Currently, training of future teachers for middle school and high school in North Macedonia can be completed in a single semester beyond the regular 3- or 4-year university education. Comparing this to the time it takes to train teachers in most European countries, a foremost recommendation would be to extend the training time of trainee teachers. Further, a thorough revision of the existing training mechanisms should be performed, and priority should be given to novel contents and teaching methods.

An even graver issue of the teacher training programs in North Macedonia is that the selectivity of candidates to be enrolled is virtually nonexistent, and everyone who wishes to become a teacher can get into a program and complete it in a couple of months, regardless of how suitable or unsuitable the previous preparation and professional competences of the candidate are. This not only buries every hope of improving the educational outcomes, but also negatively impacts the willingness of better prepared candidates to enter such programs. It is of primary importance in North Macedonia, therefore, to ensure that both the entry and the progression in the teaching career are competitive and based on well-defined and meaningful measures of competence, achievements and merit.

Along with the extended training period, a probationary school year shall be introduced for all new teachers, with a clearly defined program for further training during the probationary year and corresponding criteria for assessing the competence of the teacher acquired during the training period and during the probationary year.

During the teacher training, aspiring teachers ought to be familiarized with more various models and strategies in order to provide width of the training. Equally important is, however, to provide in-depth special training for instructors for their particular fields of specialization.

One of the chief priorities of the reform shall be to prepare an effective program for the role of teacher mentors, as part of the cascading training mechanism, and to make their training a priority.

According to the findings outlined in the 2019 OECD Assessment, during the training phase, teachers ought to be acquainted with the need to continuously assess the fulfillment of the curriculum expectations and adjust the teaching process in a way to reduce the possibility that students move through school without acquiring competencies.

Schools should become supportive communities for the continuing professional development of teachers through teacher activities, appraisal and support teams. While schools in North Macedonia have a wide range of support capabilities on paper, currently due to the lack of organizational culture and funding for the improvement of the educational environment, the practical results are lagging behind those of most OECD countries.

Schools should have at their disposal a wide range of vocational training instructors, as well as means and tools of vocational training, leaving them room to freely determine the best resources to utilize according to their particular needs. More opportunities for exchange of expertise between teaching instructors should be created, with greater utilization of possibilities within the educational institutions.

A more precise definition of the role of school principal and the school officials, especially in terms of their job 
description and employment contract is necessary. The training of the school principals should be a prerequisite for their appointment, and the continuing upgrading of their skills should be a requirement for maintaining the position. The school principals and school officials ought to be responsible for the preparation of the development plan of the school, within which the priority of the training will be determined.

Lastly, the Ministry of Education and Science ought to build the strategy based on the positive experiences from the previous and ongoing pilot projects, and to make the results and deliverables of those projects widely available via electronic publications.

\section{CONCLUSION}

In this paper we argued that diversification of the education forms, in contrast to classical education models, through well thought out and planned reforms is necessary for ensuring employability and subsistence in unpredictably changing living conditions.

No school, no faculty today, when everything is changing so fast, can pretend to form educated people with complete and final knowledge in their future profession. The fundamental task of educational institutions, then, becomes for endow their students with a culture of learning throughout their lives, as a necessity and requirement for successful professional orientation and guaranteed subsistence in the ever changing living conditions of today.

It must be acknowledged that even the developed countries cannot boast that they have harmonized the classical education system with the needs for additional education for retraining and vocational training. The Republic of North Macedonia is far from the goal in this regard; this proposal implies a completely different approach from what is happening in the schools and universities of the country at present.

\section{REFERENCE LIST}

Law on Primary Education of the Republic of North Macedonia, Official Gazette of the Republic of North Macedonia, No. 161/2019 and 229/2020.

Law on Secondary Education of the Republic of North Macedonia, Official Gazette of the Republic of North Macedonia, No. 229/2020.

Law on Training and Examination for a Principal of a Primary School, High School, Dormitory and Open Civic University for Lifelong Learning, Official Gazette of the Republic of North Macedonia, No. 10/2015, 145/2015, 192/2015, 30/2016, 120/2018 and 140/2018.

Law on Vocational Education and Training, Official Gazette of the Republic of North Macedonia, No. 275/2019.

Law on Higher Education of the Republic of North Macedonia, Official Gazette of the Republic of North Macedonia, No. 82/2018.

State Statistical Office of the Republic of North Macedonia, National Classification of Occupations, Skopje 2015.

OECD, Review of Evaluation and Assessment in Education in North Macedonia, 2019 